\title{
Optimising the number of teaching and researching staff within Croatian higher education system
}

\author{
Branka Marasović ${ }^{1, *}$, Ivana Tadić ${ }^{1}$ and Tea Kalinić ${ }^{1}$ \\ ${ }^{1}$ Faculty of Economics, Business and Tourism, University of Split \\ Cvite Fiskovića 5, 21000 Split, Croatia \\ E-mail: $\langle\{$ bmarasov, itadic, tkalinic $\} @ e f s t . h r\rangle$
}

\begin{abstract}
Human resources represent crucial resource and capital for any organization's success, because they generate knowledge, skills, abilities and experience which distinguish organizations and emphasize their competitive advantage. Nowadays, managers are struggling in their competition in order to maximize performance results and other positive effects obtained by their crucial resource and in the same time minimizing production costs and other belonging losses. Although, higher education does not represent production in the true sense of the word, management leads the same battle, related to faculty teaching and researching staff workload, setting goals and various constrains.

The main aim of this paper is optimization of human resource allocation within Croatian higher education system, according to several goals, related to their teaching and researching staff workload, minimizing deviation from set goals defined according to Croatian higher education regulations. The paper suggests the use of integer goal programming model in order to find optimal solution presented with the number of teachers and researchers within each department of chosen faculty. The model will be applied to the example of Croatian faculty, due to certain specificities of Croatian higher education system and will be applicable to any other Croatian faculty. Different optimal model solutions, obtained for different number of goals, will be compared within the paper. This model will secure optimal level of teaching and researching positions, considering multiple goals, with the emphasize of evolution and progression on individual level, simultaneously providing the best quality for students, as well as competitive and profitable work of the institution.
\end{abstract}

Keywords: higher educational system, human resource allocation, integer goal programming

Received: October 5, 2018; accepted: April 11, 2019; available online: July 4, 2019

DOI: $10.17535 /$ crorr.2019.0010

\section{Introduction}

Higher education institutions, the same as companies, are focused in achieving different aspects of business, such as: higher performances, quality of work, lower costs of work and employees' satisfaction. In order to optimally combine all previously mentioned aspects of business, any organization should provide proper planning of human resources, as the first group of required activities within human resource management. It includes planning the number of employees within organization and their proper allocation and workload, not neglecting planning the crucial requirements for their allocation, like knowledge, skills, abilities or employees' motivation towards work.

Therefore, the paper presents model for optimization of human resource allocation within Croatian higher education system, according to several goal constraints, related to their teaching and researching staff workload. The rest of the paper is structured as follows. Section 2 provides

${ }^{*}$ Corresponding author. 
a definition of human resources planning and presents its importance in achieving competitive advantage for any organisation. Also, it reviews several different human resource planning examples with the help of which it notes mathematical programming as one of the appropriate methods in human resource planning. Section 3 discusses relations between human resource planning and higher education systems, with special emphasis on Croatian higher education systems. Section 4 provides mathematical model for finding optimal solution in human resource allocation, within the higher education institution. Section 5 discusses results obtained by applying the previous model to Croatian Faculty. Section 6 summarises and points towards directions for any future research.

\section{Mathematical programming models in human resource planning}

"Human resource (HR) planning is the process of analysing and identifying the need and availability of human resources so that the organization can meet its objectives. The focus of HR planning is to ensure the organization has the right number of human resources, with the right capabilities, at the right time, and in the right place" [9]. These or similar definitions have been in use for many decades now. However, these definitions are criticized for lack of clarity, asking the question what is right and by whom it is defined. Contemporary and clearer definition can explain HR or workforce planning as a process in which an organization attempts to estimate the demand for labour and evaluate the size, nature and resources of supply which will be required to meet the demand [4]. Of course, all mentioned factors (number of employees, their knowledge, skills and abilities, workplace and timing) should be taken into consideration in order to provide organizational goals and sustained competitive advantage for any organisation.

However, if managers focus only on certain aspects of HR planning, it will lead to inappropriate decision making, employing inadequate employees or being faced with labour surplus or shortage. Finally, those will cause different organizational problems and unpredicted costs, but also create major problems to their employees (poor motivation, dissatisfaction, stress, overwork, no potential for development). "Some major issues are related exclusively to employers, such as: lower productivity, loss of competition, problems within industry, loss of crucial human capital, higher salary costs or cost of terminations" [15].

Although, HR planning can be a short term issue. Usually it is meant for long term purposes. Moreover, if it is provided in correlation with entire (strategic) human resource management system of particular organisation in which it contributes to organizational success. HR allocation is lately of great interest of many researches in the literature [2] and applied in different business disciplines in practice. For instance, some interesting examples of HR allocation are evident in biotech start-up company [13], government organisations [11] or within multi-projects management [12]. In general, managers use different qualitative and quantitative methods and techniques to derive optimal solutions and increase their business results in different managerial fields as well as within HR planning. Therefore, mathematical programming models represent quantitative methods which are often in use in order to derive optimal solutions in HR allocation. Practical applications of these models, which many researches used in their research problems, will be further explained in more details. Hence, some interesting researches in HR allocation were provided within health industry. [10] applied goal programming method in health industry to propose the optimal number of physicians in public and private sectors with one and two working shifts. The results of the model showed that allocation of HR in family physician program was not optimal and satisfactory which required goal programming method to provide a more favorable allocation. Decision variables applied in this model included optimal number of family physicians who worked in different shifts in public and private sectors in chosen locations, while goal and systematic constraints were based upon existed laws and regulations (budget constraints, constraints of the population covered by the physicians, constrains of the number of assistants, non-negative systematic constraints, constraints of population in 
particular locations, constraints of the number of governmental and private health centers and finally constraints of working shifts). Also, a $0-1$ linear goal programming model for nurse scheduling was developed and presented in [1] to improve the current manual-made schedules. The authors proposed model based on two classes of constrains, hard constrains that must be satisfied and soft constrains that may be violated. The new proposed model represents more efficient and less expensive model as well as model satisfying more important criteria for efficient nurse scheduling.

Some issues related to inadequate HR planning, as generally observed in business, are also crucial problems for higher education institutions. Those could be seen in similar age groups of employees which would retire at about the same age. Their talent and brain drain or crucial skill gaps finally negatively affect competitive advantage and organisational survival. Higher education institutions, also as other organisations, depend on their HR for the achievement of their goals and mission [6]. In the sense of higher education system it contributes to quality education goals provided to the total number of students. Changes and requirements which surround the field of higher education, as well as competition recognized within the growing number of new faculties and higher schools, demand constant growth and development of current employees (teachers, researchers and other faculty members), which is very often limited by financial constraints and defined policies and measures.

Therefore, there is an example of managing and allocating faculty resources at University of South Indiana. This research revealed application of goal programming technique. This method was provided for university in order to hire the most qualified faculty members, providing top quality for their students and in the same time minimizing it costs. For this purpose, five goals were defined: "to cover the required course hours, to maintain faculty split of $80 \%$ full-time and $20 \%$ part-time, to maintain $65 \%$ terminal degree coverage rate of full-time faculty, to attain a desired distribution of faculty with respect to rank and finally to minimize costs" [8]. Another group of authors [5] applied linear programming to optimize the use of resources, also in higher education. The authors based their research upon 5 faculties which are available to teach 5 different courses in a particular class. Their task was to determine which available faculty can be the best to teach a particular course in order to get the best faculty to teach the course and lead to better results. Using linear programming, the faculty best fit to teach a particular subject was calculated. Application of mathematical models in HR allocation was also presented within [3]. Paper explains application of multi-objective optimisation method in HR allocation in order to be aligned with institutional strategic plans within chosen university. [18] proposed human capital planning model based on analytic hierarchy process, with the help of which the dimension for faculty number of each school university could be obtained according to the performance of assessment of teaching, research and service. [15] already provided research optimizing HR allocation within Croatian higher education system in terms of minimising employees' costs, but in the same time determining the required number of teaching and researching staff who will fulfil all their duties.

Since, the cost minimisation or any other financial issues are not primary goals in higher education system, but there are many important goals oriented more towards the increase of higher education quality delivered to students, there is a need to observe HR allocation as the problem of multicriteria decision. According to specificities of the problem which represent the scope of this paper, goal integer programming model will be presented in order to allocate HR in higher education system.

\section{Progress within higher education system in Croatia}

Development within each higher education system, as well as investments in higher education system should be in focus of each county, because it will provide the country with educated, skilled and experienced individuals and teams of future employees, who will finally support 
enrichment of entire society, create competitive advantage for different entities and create individual wellbeing. The main goal of each higher education system is education of high quality individuals, which requires adequate human resources, as the most important resources in the aforementioned process. Besides, many important employees in higher education institutions who provide and support educational process, teaching and researching staff represent essence of educational and developmental process. Their academic work is not based exclusively on teaching, although it is one of their major duties, but requires substantial involvement in research, project work or scientific publications in order to provide the best possible outcomes to their students. However, workload is not the only problem or limitation that teaching and researching staff is faced with. Often, lack of other resources, primarily financial burdens potential development and the work the experts have done.

Consequently, Croatia is an example of developed country which understands the importance of continuous investments in education and pays attention in securing the most important educational goals. However, unavoidable financial resources constrain its full potential and development. "Nevertheless, in order to secure high quality education system in Croatia, higher education institutions employ quality researching and teaching staff whose main objective is to evolve and progress on individual level during their entire work life, creating high quality of education for their students and recognition and competitive advantage for the entire institution $"$ " [15]. In order to fulfil its main objective, Croatian education system recognizes different researching and teaching positions. Those include: (1) junior researcher, (2) postdoctoral researcher, (3) assistant professor, (4) associate professor, (5) full professor, (7) lecturer and (8) senior lecturer (according to [17]), advancing from position of junior researcher to the position of full professor which requires fulfilment of certain conditions (in terms of researching and teaching and minimum time spent at each position). Lately, the process of their progress has evolved through certain changes. Namely, education system enabled teaching and researching staff to advance in a period of 5 years regularly, or has provided them with the possibility of earlier advancement after the period of 3 years. As far as the maximum length of time that members of teaching and researching staff have been able to stay at the same position, was the period of 10 years, providing them with the possibility to stay at the same position twice in a sequence fulfilling defined requirements.

However, crisis and insufficient investments have lately affected Croatian higher education system. "Currently, there is evident deficiency in funding within different areas of education system which decreases possibilities for personal development and advancement. Additionally, another change has occurred in terms of staff advancement, meaning that Croatian faculty staff is not faced with the possibility of earlier advancement any more, regardless of their performing results. Although, if their results are exceptional, members of faculty staff have the possibility to advance minimum 5 years after being placed at their previous position, because of insufficient funds for increasing base pays caused by their advancement.

Moreover, financial problems can also cause situation in which they may stay at the same position even after 5 years, disregarding their substantial efforts and results and waiting for (financial) better times. Advancement after 3 years is only possible for members of staff who fulfil requirements for the next two positions in advance, meaning that assistant professor can be promoted after 3 years to the position of associate professor only fulfilling all requirements equivalent to the position of full professor" [15].

Croatia is currently faced with the problem of employment of young scientists. Firstly, potentials for new employments are decreasing from year to year. Additionally, the number of reputable scientists who are emigrating worldwide is considerably increasing. Those problems ask for prompt solutions; is there any opportunity to change HR allocation within Croatian higher education institutions and what can be done in order to solve it? This paper will present mathematical model which will create potential for adequate understanding and decision making related to previously stated problem. 


\section{Research method}

Mathematical programming is widely used to find optimal solution for a mathematical problems in different situations. The productivity of each organization often depends on expert analysis of the default problem, its mathematical formulation, and the correct application of carefully selected methods in mathematical programming.

Example is higher education system and its proper work which should be one of the most important deals in every country because it depends on the level of state's competitiveness in the production of labour force as well as scientific experts. The quality of higher education system depends on multiple different variables, but one of them is HR allocation. Therefore, the model of finding optimal solution in HR allocation, within the higher education institution, will be presented below.

Teaching and researching staff, according to their scientific interest, are divided into $d$ standard departments and one special department for physical education end foreign languages. Suppose that staff of each standard department consists of junior researchers, postdoctoral researchers, assistant professors, associate professors and full professors. Staff of special department are lecturers. So, the total number of positions on faculty is $n=5 d+1$.

The models input data for each position are:

- number of teaching hours (tutorials and lectures)

- average gross salary

- number of students

- number of final thesis

- number of master thesis

- proportion of assistants (junior researchers, postdoctoral researchers) and professors (assistant professors, associate professors, full professors)

If each of $n$ positions represents one variable $x_{i}, i=1,2, \ldots, n$, the main aim is to find the optimal number of employee on each position, within each department, according to model inputs, resulting lowest deviations from the following goal values:

- total number of hours (tutorials and lecturing) per departments

- total salary cost

- total number of students

- total number of final thesis

- total number of master thesis

- satisfying assistant-professor proportion per standard department

Considering that more criteria are set within given goal values, the goal programming is applied as method of mathematical programming. Taking into account that, because of their definition, the variables $x_{i}, i=1,2, \ldots, n$ must be integer (as well as non-negligible), their determination becomes the problem of integer goal programming.

So far, presented model consists of variables $x_{i}, i=1,2, \ldots, n$ and $m$ goal values. Each of $d$ standard departments has goal value for total number of tutorials, total number of lectures and satisfying assistant-professor proportion. Special department has goal value for total number of hours, given that the lecturers are teaching both, lectures and tutorials. Hence, so far $3 d+1$ goal values are listed. The remaining four goal value, from list above, refer to general faculty business, therefore the total number of goal values is $m=3 d+5$. Two additional variables, 
$d_{i}^{-}, d_{i}^{+}, i=1,2, \ldots, m$ for each goal value, represent how much a model achieved value is under or over goal value. The objective of integer goal programming is to find values $x_{i}, i=1,2, \ldots, n$, with the aim to the sum of deviations $d_{i}^{-}+d_{i}^{+}, i=1,2, \ldots, m$ of all goals constraints is the minimum. A major issue of debate within goal programming community has concerned the use of normalisation techniques to overcome incommensurability which occurs when deviational variables measured in different units are summed up directly. This simple summation will cause an unintentional bias towards the objectives with a larger magnitude. This bias may lead to erroneous or misleading results. One suggestion to overcome this difficulty is to divide each objective through by a constant pertaining to that objective, called normalisations constant. There are several different normalisation, but in this model zero-one normalisation will be implemented. The normalisation constant in this model is equal to the distance between goal value and the worst possible value for the relevant deviational variable [16].

The mathematical formulation of the model follows:

$d$ - number of standard departments,

$x_{i} \in \mathbf{N}_{\mathbf{o}}, i=1,2 \ldots, n=5 d+1$ - number of employees at a single position,

$b_{i}, i=1,2, \ldots, m$ - goal values,

$d_{i}^{-}, i=1,2, \ldots, m-$ under deviations of goal value,

$d_{i}^{+}, i=1,2, \ldots, m$ - over deviations of goal value,

$d_{i}^{-} \cdot d_{i}^{+}=0, i=1,2, \ldots, m$.

$A \sim m \times(n+2 m)$ - matrix of inputs for all departments and positions, with elements:

$(\forall i \in\{1,2, \ldots, d\})(\forall j \in\{1, \ldots, 5\})(\forall k \in\{1, \ldots, m\})$

$a_{2 i-1,5 i-5+j}$ - hours of tutorials for $j^{\text {th }}$ position on $i^{\text {th }}$ department,

$a_{2 i, 5 i-5+j}$ - hours of lectures for $j^{\text {th }}$ position on $i^{\text {th }}$ department,

$a_{2 d+1,5 d+1}$ - hours of tutorials and lectures for special department,

$a_{2 d+2,5 i-5+j}$ - average gross salary for $j^{t h}$ position on $i^{t h}$ department,

$a_{2 d+3,5 i-5+j}$ - number of students for $j^{t h}$ position on $i^{\text {th }}$ department,

$a_{2 d+4,5 i-5+j}$ - number of final thesis for $j^{t h}$ position on $i^{\text {th }}$ department,

$a_{2 d+5,5 i-5+j}$ - number of master thesis for $j^{t h}$ position on $i^{t h}$ department,

$\left[a_{2 d+5+i, 5 i-4}, a_{2 d+5+i, 5 i-3}, a_{2 d+5+i, 5 i-2}, a_{2 d+5+i, 5 i-1}, a_{2 d+5+i, 5 i}\right]$ - proportion of assistants and professors on $i^{\text {th }}$ department refers to relation:

$$
\frac{a_{2 d+5+i, 5 i-4}+a_{2 d+5+i, 5 i-3}}{a_{2 d+5+i, 5 i-2}+a_{2 d+5+i, 5 i-1}+a_{2 d+5+i, 5 i}}=r,
$$

$a_{k, n+2 k-1}=1, a_{k, n+2 k}=-1$ - implementation of $d^{-}, d^{+}$definitions.

For all other elements that are not specified above, $a_{p q}=0$.

$B=\left[b_{1}, b_{2}, \ldots, b_{m}\right]^{\tau}$ - vector of goal values:

$(\forall i \in\{1,2, \ldots, d\})$

$b_{2 i-1}$ - hours of tutorials for $i^{t h}$ department,

$\mathrm{b} b_{2 i}$ - hours of lectures for $i^{\text {th }}$ department,

$b_{2 d+1}$ - hours of tutorials and lectures for special department, 
$b_{2 d+2}$ - total gross salary,

$\mathrm{b} b_{2 d+3}$ - total number of students,

$b_{2 d+4}$ - total number of final thesis,

$\mathrm{b} b_{2 d+5}$ - total number of master thesis,

$\mathrm{b} b_{2 d+5+i}=a_{2 d+5+i, 5 i-4}+a_{2 d+5+i, 5 i-3}-r \cdot a_{2 d+5+i, 5 i-2}-$

$-r \cdot a_{2 d+5+i, 5 i-1}-r \cdot a_{2 d+5+i, 5 i}$.

In accordance with zero-one normalisation, the following vectors are introduced:

$w_{i}^{-}, w_{i}^{+}, i=1,2, \ldots, m$ - weights of $i^{\text {th }}$ goal values deviations $d_{i}^{-}, d_{i}^{+}$,

$t_{i}^{-}, t_{i}^{+}, i=1,2, \ldots, m$ - tolerance for $i^{t h}$ goal values deviations $d_{i}^{-}, d_{i}^{+}$.

Since, the main aim is to minimise deviations from the goal values, in accordance with the all above, goal programming model formulation is given as:

$\min _{X} f \cdot X^{\tau}$, subject to $A \cdot X=B, X \geq 0$,

s.t.

$X=\left[x_{1}, x_{2}, \ldots, x_{n}, d_{1}^{-}, d_{1}^{+}, d_{2}^{-}, d_{2}^{+}, \ldots, d_{m}^{-}, d_{m}^{+}\right]$,

$f=[\underbrace{0,0, \ldots, 0}_{n}, \frac{w_{1}^{-}}{t_{1}^{-}}, \frac{w_{1}^{+}}{t_{1}^{+}}, \ldots, \frac{w_{m}^{-}}{t_{m}^{-}}, \frac{w_{m}^{+}}{t_{m}^{+}}]$.

\section{Data Analysis}

Presented model is applied to Faculty of Economics, Business and Tourism, University of Split, Croatia, with eight standard and one special department. Each standard department consists of five different position, junior researchers, postdoctoral researchers, assistant professors, associate professors and full professors, while special department only provides position of lecturers. In accordance with legal regulations and practice at the Faculty, the following assumptions are introduced.

One half of every department should consist of junior researchers and postdoctoral researchers and the other half of assistant professors, associate professors and full professors. Junior researchers and postdoctoral researchers can only provide tutorials, assistant professors and associate professors may provide both lectures and tutorials, while full professors should provide only lectures. On the special department there is no division of lessons into tutorials and lectures, as this is department for foreign languages and physical education. It is also assumed that $1 / 3$ of assistant professors teaching hours are lectures, and the rest are tutorials, while $2 / 3$ of associate professors teaching hours are lectures, and the rest are tutorials. Furthermore, the total number of tutorials and lectures is determined for each department.

Currently, 2800 students are registered on the Faculty. The assumption is that the number of students per junior researchers and per postdoctoral researchers may not exceed 15, while the limit for other positions is 30. There is total number of 180 final theses and 80 master theses per year on the Faculty. Postdoctoral researchers, may mentor only final thesis, while assistant professors, associate professors and full professors may mentor both final and master thesis. Ten final thesis and 5 master thesis is the maximum number for mentoring by each position. According to previous assumptions and information presented in Table 1, the model of goal integer programming has been formed as shown in the previous section. 


\begin{tabular}{|l|l|l|l|l|l|l|}
\hline \multirow{2}{*}{} & \multicolumn{5}{|c|}{ Standard Departments } & $\begin{array}{l}\text { Special } \\
\text { Depart. }\end{array}$ \\
\cline { 2 - 7 } & $\begin{array}{l}\text { Junior } \\
\text { Researcher }\end{array}$ & $\begin{array}{l}\text { Postdoctoral } \\
\text { Researcher }\end{array}$ & $\begin{array}{l}\text { Assistant } \\
\text { Professor }\end{array}$ & $\begin{array}{l}\text { Associate } \\
\text { Professor }\end{array}$ & $\begin{array}{l}\text { Full } \\
\text { Professor }\end{array}$ & Lecturer \\
\hline H.of Tut. & 150 & 225 & 200 & 100 & 0 & \\
\hline H. of Lect. & 0 & 0 & 100 & 200 & 300 & 450 \\
\hline $\begin{array}{l}\text { Av. Gross } \\
\text { Salary } \\
\text { (kn) }\end{array}$ & 8626.41 & 11330.42 & 13240.38 & 14982.54 & 18251.41 & 10397 \\
\hline $\begin{array}{l}\text { Nb. of } \\
\text { Students }\end{array}$ & 15 & 15 & 30 & 30 & 30 & 30 \\
\hline Fin.Thesis & 0 & 10 & 10 & 10 & 10 & 0 \\
\hline Mast.Thesis & 0 & 0 & 5 & 5 & 5 & 0 \\
\hline $\begin{array}{l}\text { Assist.- } \\
\text { Prof.Prop. }\end{array}$ & $50 \%$ & \multicolumn{5}{|c|}{$50 \%$} \\
\hline
\end{tabular}

Table 1: Input data for a single position

The model has 99 variables, of which 41 variables $x_{i}, i=1,2, \ldots, 41$ representing the number of employees at each position, and 58 deviation variables $d_{i}^{+}, d_{i}^{-}, i=1,2, \ldots, 58$ for 29 goal values $b_{i}, i=1,2, \ldots, 29$. The optimal solution for three different scenarios is obtained by MATLAB and presented in Tables $2 \mathrm{a}-2 \mathrm{~b}$.

\begin{tabular}{|c|c|c|c|c|c|c|c|c|c|c|c|}
\hline & S.1 & $\mathrm{S} .2$ & S.3 & & S.1 & S.2 & S.3 & & S.1 & S.2 & S.3 \\
\hline $\mathrm{x} 1$ & 8 & 8 & 5 & x34 & 0 & 3 & 0 & d13+ & 0 & 0 & 0 \\
\hline $\mathrm{x} 2$ & 0 & 0 & 2 & x35 & 4 & 2 & 4 & d14- & 0 & 0 & 0 \\
\hline $\mathrm{x} 3$ & 0 & 0 & 0 & x36 & 1 & 4 & 7 & d14+ & 0 & 0 & 0 \\
\hline $\mathrm{x} 4$ & 0 & 0 & 0 & x37 & 5 & 3 & 0 & d15- & 0 & 0 & 0 \\
\hline $\mathrm{x} 5$ & 7 & 7 & 7 & $\mathrm{x} 38$ & 0 & 0 & 1 & d15+ & 15 & 15 & 90 \\
\hline $\mathrm{x} 6$ & 8 & 6 & 8 & $\mathrm{x} 39$ & 0 & 0 & 1 & d16- & 0 & 0 & 0 \\
\hline $\mathrm{x} 7$ & 1 & 1 & 1 & $\mathrm{x} 40$ & 6 & 6 & 5 & d16+ & 0 & 0 & 0 \\
\hline $\mathrm{x} 8$ & 0 & 0 & 0 & $\mathrm{x} 41$ & 4 & 4 & 4 & d17- & 90 & 90 & 90 \\
\hline $\mathrm{x} 9$ & 1 & 4 & 1 & d1- & 0 & 0 & 0 & d17+ & 0 & 0 & 0 \\
\hline $\mathrm{x} 10$ & 8 & 6 & 8 & d1+ & 0 & 0 & 0 & d18- & 619674 & 623571 & 645766 \\
\hline $\mathrm{x} 11$ & 8 & 8 & 3 & d2- & 0 & 0 & 0 & d18+ & 0 & 0 & 0 \\
\hline $\mathrm{x} 12$ & 1 & 1 & 3 & d2+ & 60 & 60 & 60 & d19- & 0 & 0 & 0 \\
\hline $\mathrm{x} 13$ & 1 & 1 & 1 & d3- & 5 & 5 & 5 & d19+ & 65 & 95 & 20 \\
\hline $\mathrm{x} 14$ & 0 & 0 & 3 & d3+ & 0 & 0 & 0 & d20- & 0 & 0 & 0 \\
\hline $\mathrm{x} 15$ & 4 & 4 & 2 & d4- & 40 & 40 & 40 & $\mathrm{~d} 20+$ & 500 & 470 & 590 \\
\hline $\mathrm{x} 16$ & 8 & 8 & 2 & $\mathrm{~d} 4+$ & 0 & 0 & 0 & d21- & 0 & 0 & 0 \\
\hline $\mathrm{x} 17$ & 0 & 0 & 4 & d5- & 10 & 10 & 10 & d21+ & 210 & 215 & 220 \\
\hline $\mathrm{x} 18$ & 0 & 0 & 0 & $\mathrm{~d} 5+$ & 0 & 0 & 0 & d22- & 0,5 & 0 & 0 \\
\hline $\mathrm{x} 19$ & 0 & 0 & 0 & d6- & 0 & 0 & 0 & $\mathrm{~d} 22+$ & 0 & 0 & 0 \\
\hline $\mathrm{x} 20$ & 6 & 6 & 6 & d6+ & 10 & 10 & 10 & d23- & 0 & 0 & 0 \\
\hline $\mathrm{x} 21$ & 13 & 13 & 7 & d7- & 0 & 0 & 0 & $\mathrm{~d} 23+$ & $6.25 \mathrm{E}-16$ & 0 & 0 \\
\hline $\mathrm{x} 22$ & 1 & 1 & 5 & $\mathrm{~d} 7+$ & 0 & 0 & 0 & d24- & 2 & 0 & 0 \\
\hline $\mathrm{x} 23$ & 1 & 1 & 0 & d8- & 0 & 0 & 0 & $\mathrm{~d} 24+$ & 0 & 0 & 0 \\
\hline $\mathrm{x} 24$ & 0 & 0 & 2 & d8+ & 0 & 0 & 0 & d25- & 1 & 0 & 0 \\
\hline $\mathrm{x} 25$ & 11 & 11 & 10 & d9- & 0 & 0 & 0 & $\mathrm{~d} 25+$ & 0 & 0 & 0 \\
\hline
\end{tabular}

Table 2a: Optimal solutions 


\begin{tabular}{|c|ccc|c|ccc|c|ccc|}
\hline & S.1 & S.2 & S.3 & & S.1 & S.2 & S.3 & & S.1 & S.2 & S.3 \\
\hline $\mathbf{x 2 6}$ & 10 & 12 & 7 & d9+ & 5 & 5 & 5 & d26- & 1 & 0 & 0 \\
\hline $\mathbf{x 2 7}$ & 0 & 0 & 2 & $\mathbf{d 1 0 -}$ & 20 & 20 & 20 & $\mathbf{d 2 6 +}$ & 0 & 0 & 0 \\
\hline $\mathbf{x 2 8}$ & 1 & 0 & 0 & $\mathbf{d 1 0 +}$ & 0 & 0 & 0 & $\mathbf{d 2 7}-$ & 0,5 & 0 & 0 \\
\hline $\mathbf{x 2 9}$ & 2 & 1 & 4 & $\mathbf{d 1 1 -}$ & 20 & 20 & 20 & $\mathbf{d 2 7 +}$ & 0 & 0 & 0 \\
\hline $\mathbf{x 3 0}$ & 6 & 7 & 5 & $\mathbf{d 1 1 +}$ & 0 & 0 & 0 & $\mathbf{d 2 8}-$ & 0 & 0 & 0 \\
\hline $\mathbf{x 3 1}$ & 1 & 2 & 4 & $\mathbf{d 1 2 -}$ & 40 & 40 & 40 & $\mathbf{d 2 8}+$ & 0,5 & 0 & 0 \\
\hline $\mathbf{x 3 2}$ & 2 & 0 & 0 & $\mathbf{d 1 2}+$ & 0 & 0 & 0 & $\mathbf{d 2 9 -}$ & 0 & 0 & 0 \\
\hline $\mathbf{x 3 3}$ & 0 & 0 & 0 & $\mathbf{d 1 3 -}$ & 15 & 15 & 15 & $\mathbf{d 2 9 +}$ & $6.25 \mathrm{E}-16$ & 0 & 0 \\
\hline
\end{tabular}

Table 2b: Optimal solutions (continued)

\begin{tabular}{|c|c|c|c|}
\hline & S.1 & S.2 & S.3 \\
\hline Sum of Deviations & 3,666667 & 3,666667 & 4,5 \\
\hline $\begin{array}{c}\text { Total Number } \\
\text { of Employees }\end{array}$ & 129 & 130 & 124 \\
\hline Total Salary Cost & 1680326 & 1676429 & 1654234 \\
\hline
\end{tabular}

Table 3: Results of comparison

In scenario 1, emphasis is placed on goal values related to the number of the hours of tutorials and lectures, per department. The under and over deviations are tolerated for a maximum of 90 hours. Scenario 2 is an extension of the previous scenario formed by requirement that the total number of students, final thesis, master thesis and total gross salary must be as close as it's possible to the goal value.

Adding to scenario 2 goal constraints that, in each department, the total number of junior researchers and postdoctoral reseachers must be equal to the total number of assistant professors, associate professors and full professors with maximum tolerance \pm 1 , scenario 3 was formed.

In S.1 column of Table 3, the result of scenario 1, shows that almost every department has the largest number of junior researchers and full professors regard to the other positions. Since the scenario 1 is limited only to goal constraints related to the hours of tutorials and lectures and junior researchers have the largest number of tutorials, while full professors have largest number of lectures, the obtained result was expected. The introduction of additional criteria in scenario 2 did not affect the value of sum of deviations, although MATLAB provided other solutions. Values of deviations of observed goals and sum of deviations in Table 3, show that optimal solution of scenario 2 is also optimal solution of scenario 1 , as well as any of their convex combination.

By introducing assistant-professor proportional rule in scenario 3, optimal solution suggests better distribution among positions. Therefore, as it is presented in the S.3. column of Table 3 , in most departments, positions with low number of employees in previous scenarios are filled more or left unchanged. The total number of employees, and total salary cost are lower then in previous scenarios, with the impact on greater sum of deviations.

The present situation at the observed Faculty differs considerably from the optimal solution obtained with the presented model. There are currently 84 members of teaching and researching staff at the Faculty, of which there are only 6 junior and postdoctoral researchers. Also, total gross salary is equal to 2.407.001,63 HRK (teaching and researching staff included employees from technical and administration offices) [7]. Additionally, it is important to mention that all teaching and researching staff is currently work loaded with $20 \%$ above the regular number of teaching hours set by statutory provisions. Obtained optimal solutions gives HR allocation plan with higher number of teaching and researching staff, as well as with the lowest salary costs, in relation to the current situation. 


\section{Conclusion}

Presented model, established on goal programming theory, and obtained result suggest potential way of workforce distribution by departments according to different number and type of goals. It shows the way to organise the number of employees on different positions, with different abilities (nb. of tutorial, lectures, final thesis and so on), on multiple departments with the aim of minimizing deviations from several goals. The assumed goals are related only to education, but due to the fact that the Faculty is a scientific-educational organization, therefore, upgrading the model to scientific goals would be desirable. Also, the assumption of equaly weighted goals can be modified on the basis of previous experience and considerations within the observed institution. If the results were applied to organizing employees in the practice, this would result in the dismissal of a large number of employees. Since the Faculty is not an emerging organization, in future work, the problem can be shaped in the sense of re-balancing the existing schedule and presenting a plan for recruiting new employees needed in the exact positions.

\section{References}

[1] Azaiez, M. N. and Al Sharif, S. S. (2005). A 0-1 goal programming model for nurse scheduling. Computers and Operations Research, 32(3), 491-507. doi: 10.1016/s0305-0548(03)00249-1

[2] Bouajaja, S. and Dridi, N. (2016). A survey on human resource allocation problem and its application. Operational Research, 17(2), 339-369. doi: 10.1007/s12351-016-0247-8

[3] Bouillard, P. (2016). A multi-objective method to align human resource allocation with university strategy. Perspective: Policy and Practice in Higher Education, 20(1), 17-23. doi: 10.1080/13603108.2015.1081303

[4] Crawshaw, J. R., Budhwar, P. S. and Davis, A. (2014). Human Resource Management: Strategic and International Perspectives. London: Sage.

[5] Das, S., Verma, S. And Gupta, M. (2017). Human Resource Allocation Model using Linear Programming. International Journal on Emerging Technologies, 8(1), 361-367. https://www. researchtrend.net/ijet/pdf/84-8F-751.pdf

[6] Fapohunda, T. M. (2015). Human Resource Planning and Succession Planning in Nigeria's Higher Education. International Journal of Research in Management and Business Studies, 2(2), 59-65.

[7] Financial Report for Faculty of Economics, Business and Tourism, University of Split, Croatia (2017). http://www.efst.unist.hr [Accessed 21/05/2018].

[8] Hermaida, R. S. and Hupfer, M. A. (1995). A Multiobjective Model For Managing Faculty Resources. Journal of Applied Business Research, 11(1), 24-29. doi: 10.19030/jabr.v11i1.5888

[9] Mathis, R. L. and Jackson, J. H. (2008). Human Resource Management (12th Ed). USA: Thomson South-Western.

[10] Mehrolhassani M. H. and Kohpeima, J. V. (2016). Application of goal programming to improve human resource allocation for urban family physician plan in Iran. Journal of Health Management and Informatics, 3(3), 94-99. http://jhmi.sums.ac.ir/index.php/JHMI/article/view/245

[11] Nikoei, M. R., Jamshidi, Z. and Sharifabadi, A. M. (2013). Presentation of Mathematical Model of Human Resource Allocation in Organisations with Organisational Cost Reduction Orientation (Case Study: Finance and Economy Affairs Organisation Ardakan Township). International Research Journal of Applied and Basic Sciences, 6(2), 136-143. http://www.irjabs.com/files_ site/paperlist/r_1662_131014104531.pdf

[12] Ponsteen, A. and Kusters, R. J. (2015). Classification of Human and Automated Resource Allocation Approaches in Multi-Project Management. Procedia - Social and Behaviour Sciences, 194, 165-173. doi: 10.1016/j.sbspro.2015.06.130

[13] Saaty, T. L., Peniwati, K. and Shang, J. S. (2007). The analytic hierarchy process and human resource allocation: Half the story. Mathematical and Computer Modelling, 46(7-8), 1041-1053. doi: $10.1016 /$ j.mcm.2007.03.010

[14] Sen, N. and Nandi, M. (2012). Goal programming, its application in management sectors - special attention into plantation management: a review. International Journal of Scientific and Research Publications, 2(9), 1-6. http://www.ijsrp.org/research-paper-0912/ijsrp-p0939.pdf 
[15] Tadić, I. and Marasović, B. (2018). Analyze of human resource allocation in higher education applying integer linear programming. Proceedings of the 27th International Scientific Conference on Economic and Social Development, 266-276.

[16] Tamiz, M., Jones, D. and Romero, C. (1998). Goal programming for decision making: An overview of the current state-of-the-art. European Journal of Operational Research, 111(3), 569-581. doi: 10.1016/s0377-2217(97)00317-2

[17] Low of Scientific Activity and Higher Education. The People's Newspaper, Official Gazette of the Republic of Croatia, NN 123/2003, NN 198/2003, NN 105/2004, NN 174/2004, NN 02/2007, NN 46/2007, NN 45/2009, NN 63/2011, NN 94/2013, NN 139/2013, NN 101/2014, NN 60/2015. https://narodne-novine.nn.hr

[18] Zhang, L., Yu, X., Yang, Z. and Du, K. (2014). Human Capital Planning of Faculties in Higher Education Insitutions with Analythical Hierarchy Process Model. Journal of Human Resources and Sustainability Studies, 2(4), 224-229. doi: 10.4236/jhrss.2014.24023 